\title{
Article
}

\section{Improving the physical and mental well- being of typically hard-to-reach men: an investigation of the impact of the Active Rovers project}

Lewis, Colin, Reeves, Matthew and Roberts, Simon

Available at http://clok.uclan.ac.uk/25218/

Lewis, Colin, Reeves, Matthew ORCID: 0000-0002-3903-2910 and Roberts, Simon (2017) Improving the physical and mental well-being of typically hardto-reach men: an investigation of the impact of the Active Rovers project. Sport in Society, 20 (2). pp. 258-268. ISSN 1743-0437

It is advisable to refer to the publisher's version if you intend to cite from the work. http://dx.doi.org/10.1080/17430437.2016.1173922

For more information about UCLan's research in this area go to http://www.uclan.ac.uk/researchgroups/ and search for <name of research Group>.

For information about Research generally at UCLan please go to http://www.uclan.ac.uk/research/

All outputs in CLoK are protected by Intellectual Property Rights law, including Copyright law. Copyright, IPR and Moral Rights for the works on this site are retained by the individual authors and/or other copyright owners. Terms and conditions for use of this material are defined in the policies page.

\section{CLoK}

Central Lancashire online Knowledge www.clok.uclan.ac.uk

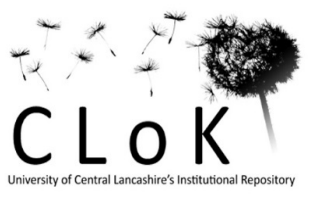



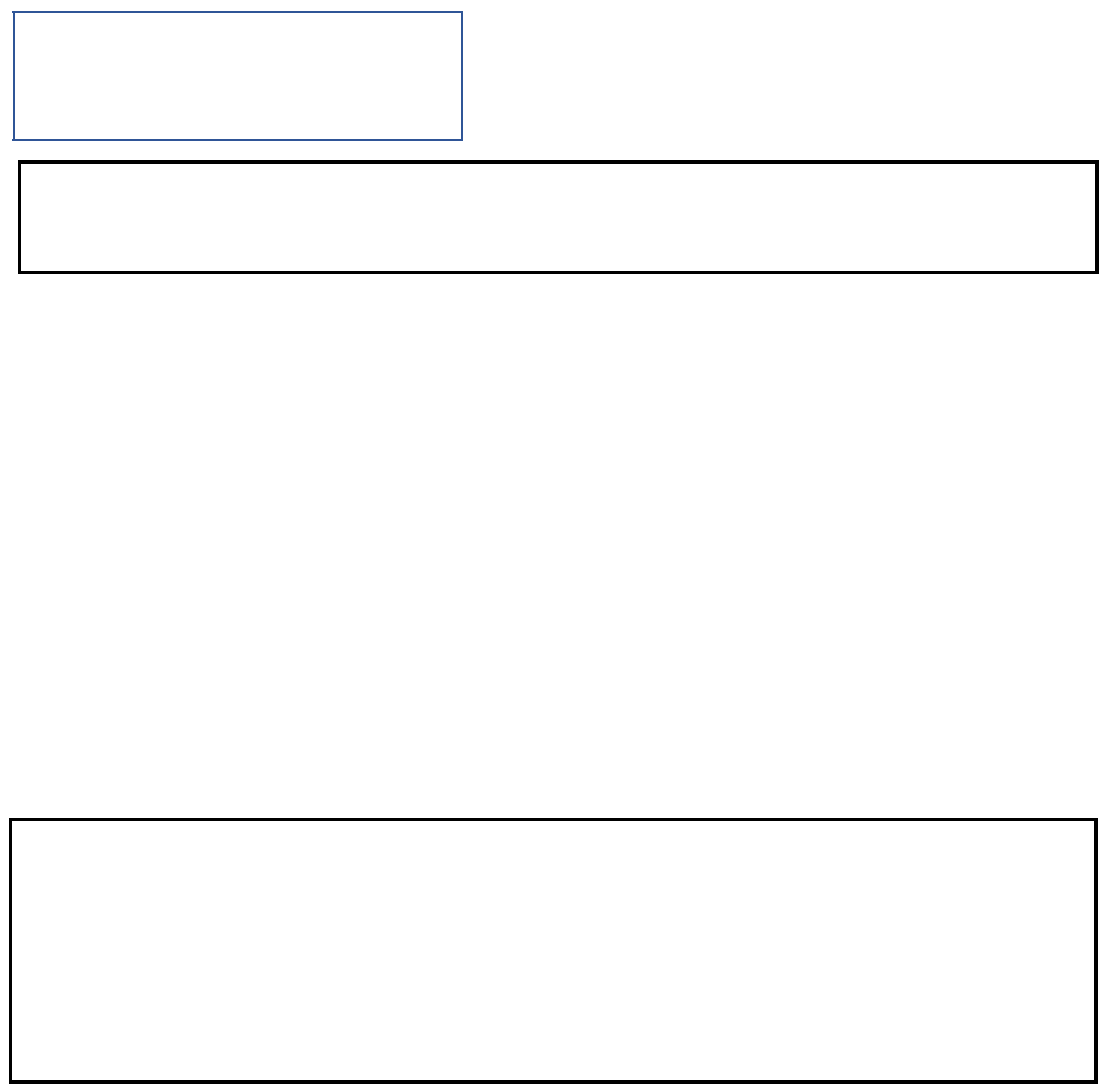
Improving the physical and mental wellbeing of typically hard-to-reach men: an investigation of the impact of the Active Rovers project

Colin J. Lewis ${ }^{1}$, Matthew J. Reeves ${ }^{1}$, Simon J. Roberts ${ }^{1}$

${ }^{1}$ School of Sport Studies, Leisure, \& Nutrition, Liverpool John Moores University, IM Marsh Campus, Barkhill Road, Liverpool, L17 6BD.

\section{Corresponding author:}

Colin J. Lewis, School of Sport Studies, Leisure, \& Nutrition, Liverpool John Moores University, IM Marsh Campus, Barkhill Road, Liverpool, L17 6BD.

\section{Contributing authors:}

c.lewis@2013.ljmu.ac.uk

m.j.reeves@1jmu.ac.uk

s.roberts2@ljmu.ac.uk 
Improving the physical and mental well-being of typically hard-to-reach men: an investigation of the impact of the Active Rovers project

\begin{abstract}
:
Strong associations exist between physical activity (PA) levels and incidence morbidity and mortality. Evidence suggests that PA levels decline with age but incidence of sedentary behaviour is high. This paper examines the effectiveness of a PA intervention hosted by a professional football club. It explores the impact of the intervention upon mental wellbeing, health perceptions, and lifestyle knowledge in men often classed as hard-to-reach (HTR). Data were collected through a shortened version of the Warwick-Edinburgh Mental WellBeing Scale, and a longitudinal self-report questionnaire. Pre- and post-intervention changes were determined by a Wilcoxon signed rank test $(P<0.05)$. Data indicated that the intervention was successful in improving aspects of mental wellbeing amongst the male client group. The qualitative findings revealed a less successful transfer from the intervention to more casual PA engagement. Professional football clubs appear to be appropriate environments to promote physical and mental wellbeing. However, behaviour change away from the football club was less obvious, suggesting further research in this area is required.
\end{abstract}

Key words: Mental health, wellbeing, football, intervention 


\section{Introduction}

Current health recommendations state that adults and older adults (50+) should do at least $150 \mathrm{~min}$ of moderate intensity exercise, or at least $75 \mathrm{~min}$ of vigorous intensity aerobic exercise per week (WHO, 2010). Yet, evidence would suggest the majority of older adults are not sufficiently active, and consequently fail to meet recommended levels of PA (Ward-Thompson et al. 2014). In the United Kingdom (UK), less than $25 \%$ of adults meet the recommended daily levels of physical activity, and thus are considered to be at a greater risk of induced medical conditions including; cardiovascular disease, type 2 diabetes mellitus, obesity, and some associated cancers (Fife-Schaw et al. 2014). A physically inactive lifestyle is also associated with poor skeletal health, debilitating mental ill health, and increased premature mortality (Hakola et al. 2015). Despite the reported positive associations between PA and health, epidemiological evidence suggests that PA levels decline with age (Sartini et al. 2015). Furthermore, PA levels of older adults are typically low and levels of sedentary behaviour high.

Older men (50+) are reported to be at the most risk from the 15 leading causes of death, and life expectancy is reported to be less than that for women, thus placing an increased burden on health services, and creating challenges for public health (Hunt et al. 2013). Despite the increase in health promotion campaigns, especially within male populations, adult male health continues to be a concern. When compared to that of women, the avoidable mortality rate for men remains disproportionately high (Robertson and Williamson, 2005), though it is important to note that this gap is closing, due to significant improvements in health interventions for men. One probable explanation for this trend is the reluctance of HTR men (as defined by unemployment, low educational attainment, poor income and social isolation) to engage with mainstream health promotion services (Robertson et al. 2013). Typical barriers for these men engaging in healthy lifestyle interventions include time, motivation, and access (Morgan et al. 2011). From a health consumption perspective, frequent attendance to health-care provision is typically considered a feminine construct (Branney et al. 2012). For instance, a study conducted by Seymour-Smith, 
Wetherell, and Phoenix (2002) revealed how GPs and practice nurses considered male attendance to be driven by a female lead. For example, a common phrase used by the men who attended the practice included 'she told me to come and see you'. The implication of this discourse is that women are considered to be active, autonomous, and conscious of self-health promotion (SeymourSmith, Wetherell, and Phoenix, 2002). Thus men have been regarded as reluctant to discuss serious health concerns (Birdis, Boggess, and Katsuranis, 1998), though evidence now suggest that men address actual symptoms around the same time as their female counterparts. However, men are less likely to engage in health promotion and preventative practices than women (Carroll, Kirwan and Lambe, 2014). The inability to influence men's ill health through traditional health avenues is often attributed to the failure of health promoting programmes meeting men's needs, especially around improving awareness and knowledge of key health issues (Zwolinsky et al. 2013).

Due to the difficulties associated with recruiting HTR men via traditional health care initiatives, and in an attempt to engage men in positive health related behaviours, the UK Government has recently financed and supported a number of alternative health related promotions (Department of Health, 2007). One such alternative includes targeted community health promotions, working in partnership with professional sport organisations. For instance, Bingham et al. (2014) conducted an older men's health intervention promotion, targeting men over the age of 55 years, within an English Premier League Football Club located in the City of Liverpool. The study did not provide any physiological evidence of change over the course of the intervention; however, the study did report some positive social and psychological benefits of the programme.

It is widely suggested that social relationships and affiliations are key determinants in positive engagements in both physical and mental health. Consequently, health promotion programmes in community settings, that promote social interaction and support are considered a viable public health option. However, despite sporting organisations providing an important social setting for health promoting policies, the dearth of controlled studies evaluating their effectiveness remains problematic (Priest et al. 2008). A notable exception however is the Football Fans in 
Training (FFiT) programme (Hunt el al. 2014). This study followed a mixed-method approach and succeeded in attracting 747 men who were at very high risk of ill-health. This particular study illustrated how professional football clubs have the potential to support health related initiatives, including weight management (Hunt et al. 2014).

Since the Priest and colleagues' review in 2008, a number of studies have demonstrated that health interventions conducted in partnership with professional sports organisations can recruit, retain and improve aspects of physical and mental health. The Premier League Health football 12week intervention programme is one such example. This particular health programme was delivered through 16 English Premier League football clubs and attempted to improve the holistic health and wellbeing of men. Despite drawing solely on self-report measures, the study demonstrated how men from diverse backgrounds, with less than optimal lifestyles, improved their health behaviour (Zwolinsky et al. 2013).

More recently, Parnell et al. (2015) conducted a secondary analysis of a PA-led health improvement programme delivered by professional football clubs for older adults aged 55+ years. Results suggested that associations with the club badge were important in accessing this participant group along with enhancing adoption and satisfaction associated with the programme.

In an attempt to better understand the effectiveness of community health promotion programmes within professional football environments, and to improve service among some client groups, researchers have adopted increasingly novel data collection protocols. For example, Curran, Drust, and Richardson (2014) advocated the adoption of a practitioner-researcher approach; in their study, the research team examined the effectiveness of a men's health campaign during match day at Everton Football Club. However, in contrast to previous football stadia methodologies, the lead author adopted an auto-ethnographic line of enquiry. Observational data, personal reflections and autobiographical notes captured first-hand, were reflexively transformed in order to give the reader a unique insight into what aspects of the FitC health programme worked, and what did not work (Curran, Drust, and Richardson, 2014). 
The purpose therefore of this paper is two-fold: The first aim is to evaluate the effectiveness of a HTRmen's health physical activity intervention programme, known as Active Rovers. Specifically, the project aim was to trial a physical activity lifestyle knowledge programme, with respect to changes in mental wellbeing, health perceptions, and lifestyle knowledge in older HTR men living in Wirral, North West England. Secondly, the paper intends to include experiences of a practitioner researcher responsible for the planning and the delivery of the Active Rovers programme.

\section{The practitioner researcher}

In an attempt to adhere to previous practitioner-research methodologies conducted within professional football settings (Curran, Drust, and Richardson, 2014), it is suggested that a profile of the researcher is provided. The practitioner-researcher (first author) was initially employed as a full-time member of Tranmere Rovers 'Football in the Community' department, based at Prenton Park, before securing a PhD studentship in 2013 at Liverpool John Moores University (LJMU), in the School of Sport Studies, Leisure \& Nutrition. The first author's role whilst employed at Tranmere Rovers FC involved coordinating the Active Rovers programme, and the day-to-day management of its delivery. This included inter alia programme design, programme development, physical activity session organisation and client satisfaction. In addition, the first author was also responsible for liaising with NHS England, with the collection of quantitative and qualitative data surrounding participant attitudes of physical, mental health and wellbeing.

\section{Methods}

Setting and context - Tranmere Rovers FC

Tranmere Rovers FC is situated within the borough of Wirral, northwest England. Wirral is a borough of contrast and diversity in terms of both its physical characteristics and social demographics. Rural areas, urban, and industrialised areas sit side by side in a compact peninsula of 
approximately 60 square miles. According to ONS (2012) data Wirral's population stands at 320,200 and has a relatively high, older population and a relatively low proportion of people in their twenties and thirties, when compared to England and Wales (ONS, 2012). For instance, Wirral has a higher proportion of its population over 45 years (male) when compared to England as a whole. Using data from the 2001 Census, over $98 \%$ of the population classified as white. In 2010-12, life expectancy in Wirral was 77.9 years for men and 81.9 years for women, compared to 79.2 years for men and 83.0 years for women in England (Wirral Economic Profile, 2014).

Within Wirral, Lower Super Output Areas (LSOAs) range from the 24th most deprived in England (i.e. Birkenhead, Tranmere, Rock Ferry, Seacombe, Bidston, and St. James) to one of the least deprived in England (i.e. Heswall). According to The Index of Multiple Deprivation (IMD) (2015) Wirral is the 2nd least deprived authority in the Liverpool City Region (IMD, 2015). Wirral is currently ranked as the 66th most deprived Local Authority (out of 326 Local Authorities in England) when ranked by average score (IMD, 2015). In the 2007 IMD Wirral was ranked 8th worst nationally for employment deprivation. According to IMD 2015 data the geographic location of Tranmere Rovers FC is within the 5\% most deprived category nationally (IMD, 2015).

\section{Characteristics of the physical activity intervention}

Active Rovers is a unique community PA-led intervention programme, designed in partnership with the 'Football in the Community' department of Tranmere Rovers FC, and NHS England. The intervention aims to improve holistic health and wellbeing of HTR men. The Football Foundation (http://www.footballfoundation.org.uk), who are the UK's largest sports charity and are financed by the Premier League, The Football Association and the Government, funded Active Rovers initially in 2010. However, the programme is now fully funded by NHS England on a yearly rolling contract.

The Active Rovers health intervention comprises of a series of mixed exercise programmes delivered on a weekly basis at Prenton Park, the home of Tranmere Rovers FC. The activities 
include football, walking football, yoga, and Tai Chi. The associated football activities were delivered by the community coaches of Tranmere Rovers 'Football in the Community' department, whose qualifications ranged from 1st4Sport Level 2 Certificate in Coaching Football to the Union of European Football Association (UEFA) B Certificate. Fully qualified health care professionals, who worked for NHS Wirral, were responsible for delivering the remaining activities (i.e. yoga and Tai chi). In addition, fully qualified staff from NHS Wirral attended weekly to conduct health checks (i.e. blood pressure, cholesterol levels, and body mass index).

Since the Active Rovers programme commenced in 2010, over 15,000 participants have registered and taken part in the designated activities. The participants were initially recruited via advertisements in Tranmere Rovers FC match-day programmes, social media outlets, and from NHS referral schemes for hard-to-reach (HTR) men. In addition, adverts were placed in the two local newspapers (i.e. The Wirral Globe and The Wirral News).

\section{Data Collection}

Initially participant demographic data were collected at registration and programme participation was tracked via attendance, and the completion of a questionnaire designed in partnership with the research team. The questionnaire included questions such as men's motivations for participation, the activities they performed, their perception of current fitness levels, any actions taken as a result of taking part in the programme (e.g. a reduction in alcohol consumption, improved dietary choices, attempting more exercise, giving up smoking, etc.). Demographic data on name, gender, date of birth, and postcode were also requested. For the purpose of this study, longitudinal data, captured from 16 men who have engaged weekly with the Active Rovers programme since its inception in 2010 were analysed.

Secondly, in order to capture the associated mental health benefits of being involved in the Active Rovers programme, a shortened scale version of the Warwick-Edinburgh Mental Well-Being Scale (SWEMWBS) was used (Stewart Brown et al. 2009). The original 14-scaled Warwick- 
Edinburgh Mental Well-Being Scale (WEMWBS) was an instrument designed to enable the measurement of mental wellbeing of adults in the UK (ibid). WEMWBS differs from other scales of mental health as it focuses only on positive aspects of mental health. Consequently, the 14 phrased Likert-style items are positively phrased (e.g. I've been thinking clearly, I've been dealing with problems well). Despite accepted levels of face validity, the original WEMWBS, however, did not meet the accepted criterion levels for measurement, as demanded by the RASCH model (ibid). The shortened, 7 item Likert-scale (SWEMWBS) however is reported to confirm to the RASCH model criteria, with an interval level transformation correlation of 0.954 to the original full scale (ibid). The final SWEMWBS scale included the following items (i.e. I've been feeling optimistic about the future, I've been feeling useful, I've been feeling relaxed, I've been dealing with problems well, I've been thinking clearly, I've been feeling close to other people, I've been able to make up my own mind about things) (ibid). Respondents completing the SWEMWBS indicated their response to a question by entering a score between 1-none of the time to 5-all of the time. For this paper, a total of 80 men who provided contact details, informed consent and verbal assent completed the pre and post SWEMWBS. Ethical approval for the study was obtained from a local university ethics committee.

\section{Data analysis}

The SWEMWBS data were entered into a spreadsheet designed specifically by Wirral Public Health for the Cheshire and Merseyside public health network (ChaMPs). Each respondent was issued with a unique alphanumeric code, which corresponded to the hard copy of the survey the respondent completed. Data were then cleaned and missing and implausible values were removed. Mean descriptives of high and low wellbeing were then calculated for before and after the project. Pre- vs. post-intervention changes were determined by a Wilcoxon signed rank test. The probability value was set at $P<0.05$. All analyses were performed using the Statistical Package for Social Science (SPSS) version 20. 


\section{Results and discussion}

The demographic data captured from the 80 men $(48 \pm 13$ years $)$ who completed SWEMWBS were consistent with the term HTR. From this group 53\% reported being unemployed and a further $12 \%$ had part-time employment; $77 \%$ had completed formal secondary school education; $63 \%$ were registered for social welfare payments; $27 \%$ were single; $17 \%$ reported being separated or divorced; $18 \%$ reported living alone.

\section{Active Rovers: participants wellbeing}

The overall SWEMWBS mental wellbeing results are displayed in Table 1. The results in Table 1 illustrate that the mental wellbeing of the participants positively increased during the course of the Active Rovers programme. The adjusted mean SWEMWBS values increased from 27.3 points to 30 points. The reported $15 \%$ increase in high levels of mental wellbeing was statistically significant $(P .<0.05)$.

\begin{tabular}{lcccc}
\hline & $\begin{array}{c}\text { Total number } \\
\text { of } \\
\text { respondents }\end{array}$ & $\begin{array}{c}\text { Pre } \\
\text { intervention }\end{array}$ & $\begin{array}{c}\text { Post } \\
\text { intervention }\end{array}$ & Change \\
\hline Demographics & $\mathrm{n}=80$ & $\mathrm{n}=80$ & $\mathrm{n}=80$ & \\
\hline Gender (male) & & & & \\
\hline$\%$ low wellbeing & $10.0 \%$ & $0.0 \%$ & $-10 \%$ \\
\hline$\%$ moderate wellbeing & $83.8 \%$ & $78.8 \%$ & $-5 \%$ \\
\hline$\%$ high wellbeing & $6.3 \%$ & $21.3 \%$ & $15 \%$ \\
\hline Mean score & & & 3.08 \\
\hline Standard deviation & 27.3 & 30 & 2.0 \\
\hline
\end{tabular}

Table 1: Participants overall SWEMWEBS mental wellbeing results 
Table 2 provides a more detailed breakdown into the individual mean SWEMWBS responses preintervention. The highest recorded mean score of (3.95 points) was associated with the question 'I've been thinking clearly'. In contrast, the lowest recorded score of (3.81 points) was associated with the question 'I've been feeling useful'.

\begin{tabular}{lccc}
\hline & $\begin{array}{c}\text { Total } \\
\text { number of } \\
\text { responses }\end{array}$ & Mean & Standard deviation \\
\hline SWEMWBS questions & & & \\
I've been feeling optimistic about \\
$\begin{array}{c}\text { the future } \\
\text { I've been feeling useful }\end{array}$ & $\mathrm{n}=80$ & 3.93 & 0.67 \\
$\quad \mathrm{n}=80$ & 3.81 & 0.71 \\
$\begin{array}{c}\text { I've been feeling relaxed } \\
\text { I've been dealing with problems }\end{array}$ & $\mathrm{n}=80$ & 3.85 & 0.62 \\
$\begin{array}{c}\text { w've been thinking clearly } \\
\text { I've been feeling close to other } \\
\text { people }\end{array}$ & $\mathrm{n}=80$ & 3.89 & 0.64 \\
$\begin{array}{c}\text { I've been able to make up my own } \\
\text { mind about things }\end{array}$ & $\mathrm{n}=80$ & 3.91 & 0.61 \\
TOTAL SWEMWBS score & & 3.91 & 0.66 \\
\hline
\end{tabular}

Table 2: Participant SWEMWBS response scores pre-intervention

Table 3 shows how four of the SWEMWBS items increased from pre- to post-intervention. For instance item 1: 'I've been feeling optimistic about the future' improved from a pre-intervention mean score of (3.93 points) to (4.35 points). At pre-intervention Item 2: 'I've been feeling useful' was reported at (3.81 points) this figure improved to (4.33 points) post-intervention. There were also pre- and post-adjusted mean differences in item 3: 'I've been feeling relaxed' (3.85 points) increased to (4.25 points) and item 4: 'I've been dealing with problems well' increased from (3.89 points) to (4.36 points). 


\section{Total number of responses Mean Standard deviation}

SWEMWBS questions

\begin{tabular}{|c|c|c|c|}
\hline $\begin{array}{l}\text { I've been feeling optimistic about } \\
\text { the future }\end{array}$ & $\mathrm{n}=80$ & 4.35 & 0.55 \\
\hline I've been feeling useful & $\mathrm{n}=80$ & 4.33 & 0.52 \\
\hline I've been feeling relaxed & $\mathrm{n}=80$ & 4.25 & 0.52 \\
\hline $\begin{array}{l}\text { I've been dealing with problems } \\
\text { well }\end{array}$ & $\mathrm{n}=80$ & 4.36 & 0.56 \\
\hline I've been thinking clearly & $\mathrm{n}=80$ & 3.95 & 0.50 \\
\hline $\begin{array}{l}\text { I've been feeling close to other } \\
\text { people }\end{array}$ & $\mathrm{n}=80$ & 3.91 & 0.56 \\
\hline $\begin{array}{l}\text { I've been able to make up my own } \\
\text { mind about things }\end{array}$ & $\mathrm{n}=80$ & 3.91 & 0.50 \\
\hline TOTAL SWEMWBS score & & 30.33 & 2.74 \\
\hline
\end{tabular}

Table 3: SWEMWBS participant scores post intervention.

\section{Absence of behaviour change away from Prenton Park}

The longitudinal questionnaire data and the face-to-face conversations revealed that the vast majority of the men now have a different perspective about the dangers associated with excessive alcohol consumption and smoking. The data also revealed the men acknowledged the positive benefits of health eating. Unfortunately, a less successful outcome of this study was the lack of PA transfer from the Active Rovers project into more casual forms of PA and associated exercise. Whilst the questionnaire data suggested that their fitness levels had increased since attending the Active Rovers sessions, it was interesting to note how a large proportion of the participants were not engaged in any additional PA externally.

From a more positive perspective, it may be that the environment (i.e. Prenton Park), or the allure of the football club, and representing the badge that was the key to maintaining the participant's motivation to engage in PA. Other professional football community based health 
studies would certainly support this supposition (i.e. Parnell et al., 2015). However, from a more pessimistic perspective, we would have anticipated any proxy measure of success, to be the participants intrinsically engaging in PA away from the Active Rovers environment. Judging by the number of men who stated that their only PA in the week was during the Active Rovers sessions then this was not the case.

Although the SWEMWBS revealed some objective statistical data to support the success of the Active Rovers project, what we were also interested in establishing was 'why?' The participant feedback questionnaire was particularly useful in this aspect, as it yielded far more detailed information surrounding the motives for continued engagement in the programme. Typically, we expected the answers to mirror the original aims of the project. To some extent this was the case, and a number of the participants comments were aligned with project brief. For example, we found evidence of participants reporting positive changes in mental wellbeing, health perceptions, and lifestyle knowledge especially in the older aged men (i.e. 50 years+).

Whist this was the case for some, it must also be noted that there were many additional motives for maintaining interest within the project. For example, when prompted to comment on the Active Rovers questionnaire regarding why they attend, the most commonly repeated responses included: 'love being a part of a group', 'like playing football and getting to know the fellas', 'to keep playing and see my mates', 'to just be active for once', and 'to lose a bit of timber of the gut'. In particular, one attendee provided feedback to the first author during a verbal dialogue:

Ian (51 years) Active Rovers Participant:

In the last questionnaire you gave us where we had to fill in our fitness levels, or well what we thought they would be at this moment in time. I put down like an 8 [Valued 1-10, 1 representing the lowest level of fitness and 10 the highest]. If I looked back at what I first put when I started taking part I'd have been lucky if I had reached 2... so I stop and think why would I stop. If I am honest this is the best I've felt in years. What's great is that, okay, it's 
great for fitness and let's be honest we all need it! If we weren't here we would just be sitting at home. But the impact that it's had on me, since I started coming and listening to you guys, it's been life changing. I'm even eating more healthily, after me and you had that chat a while ago. Plus mentally it has been great and making me feel more confident to take part and getting to know new people, some of which have become good friends of mine. You can't put a price on that!

The narrative above helps to showcase the potential positive impact of the Active Rovers programme. Interestingly, the participant reveals how the programme has helped improve aspects of both physical and mental health. However, it is perhaps the suggestion that the social aspect of the intervention, which is also illuminating.

The purpose of this particular study was to evaluate the effectiveness of Active Rovers, a PAled health improvement intervention delivered by Tranmere Rovers FC. The findings from the SWEMWBS statistical data indicate the programme was successful in improving aspects of mental wellbeing amongst its HTR male client group. For instance, there were statistically significant differences from pre-intervention to post-intervention. However, we do add a cautionary note here, as the sample size of 80 participants is modest at best, and may not be generalised to other PA-led health improvement projects. However, these findings do support previous PA-led health improvement projects conducted within professional football clubs (Hunt et al. 2014; Pringle et al. 2014).

\section{Practitioner-based-reflections}

The success of the Active Rovers project was largely due to the vigorous nature of the marketing campaign. The project team targeted typically HTR areas, and we were genuinely encouraged by the attendance figures, and perhaps more importantly the high levels of retention. Football in the Community departments such as the one at Tranmere Rovers FC should, therefore, consider a range of multi-media recruitment strategies, such as social media, local newspaper 
articles and radio stations adverts, as an effective recruitment tool and not just rely on adverts in and around the ground.

In addition, the practice of a multi-method approach to data capture was successful. Interestingly, what was effective, and helped ensure the longevity of the Active Rovers programme, was understanding the attendees' motives for their sustained engagement in the programme. Therefore, moving forward, it would be worthy to continue to acquire this data to ensure that practitioners can comprehend and appreciate this evidence and utilise it for the benefit of their future physical activity intervention programmes. In addition, measuring objective levels of physical activity may offer further insights into the impact of such programmes. Finally, the research has helped, from a practitioner perspective at least, to recognise that there needs to be more of an emphasis placed on tackling key health messages, and PA levels away from the 'magnetism' of the professional football ground. As for football clubs' community departments, perhaps branching out and delivering supplementary sessions in additional LSOAs could help to facilitate this ambition.

\section{Conclusion}

The findings from this study suggest that PA-intervention programmes such as Active Rovers, can help support associated health agencies improve aspects of health and mental wellbeing amongst typically HTR men. The use of a professional football ground, as a non-traditional health venue, appeared to act as an incentive to attract, recruit and retain this priority group in the healthbased programme. However, future research should also consider how these priority groups could also be supported away from the professional football environment. Furthermore, the multi-method approaches to data capture, as advocated by previous studies (i.e. Pringle et al. 2014; Hunt et al. 2013, 2014; Rutherford et al. 2014; and Parnell et al. 2015) are recommended for future studies in this area. 


\section{Acknowledgements}

The author(s) would like to acknowledge the staff at Tranmere Rovers FC for all their support with this research project and permission to identify the club explicitly in this publication. The author(s) would also like to thank Becky Mellor the public health manager for Wirral Council for kindly supporting the data capture process and publication plan. Furthermore, thanks must also be given to the reviewers of this paper whose comments have improved its overall quality. 


\section{References}

Bingham, D.D., Parnell, D., Curran, K., \& Richardson, D. 2014. "Fit Fans: understanding the issues and effectiveness of a health promotion programme for older men delivered within an English Premier League Football Club.” Soccer \& Society, $15 \quad$ (6): 883901. doi: 10.1080/14660970.2014.920624

Birdis, C., J. Boggess, and F. Katsuranis. 1998. “A profile of the adolescent male family planning client." Family Planning Perspective 30: 63-66.

Branney, P., K. Witty, A. Bagnall, J. South, and A. White. 2012. "Straight to the GP; that would be where I would go: An analysis of male frequent attenders' constructions of their decisions to use or not use health-care services in the UK." Psychology and Health 27: 865-880.

Carroll, P., L. Kirwan, and B. Lambe. 2014. "Engaging 'hard to reach' men in community based health promotions.” International Journal of Health Promotion Education 52: 120-130.

Carless, D. and K. Douglas. 2008. "Narrative, identity and mental health: How men with serious mental illness re-story their lives through sport and exercise." Psychology of Sport and Exercise 9: 576-594.

Curran, K., B. Drust, and D. Richardson. 2014. "I just want to watch the match: a practitioner's reflective account of men's health themed match day events at an English Premier League football club." Soccer and Society 15: 919-933.

Department of Health. 2007. Healthy Weight, Healthy Lives. London, London: HMSO.

Fife-Schaw, C., S. de Lusignan, J. Wainwright, H. Sprake, S. Laver, V. Heald, J. Orton, M. Prescott, H. Carr, and M. O’Neil. 2014. “Comparing exercise interventions to increase persistence with physical exercise and sporting activity among people with hypertension or high normal blood pressure: study protocol for a randomised controlled trail.” Trials 15: 336.

Gray, C.M., K. Hunt, N. Mutrie, A.S. Anderson, J. Leishman, L. Dalgarno, and S. Wyke. 2013. "Football fans in training: The development and optimization of an alternative intervention 
delivered through professional sports clubs to help men lose weight, become more active and adopt healthier eating habits." BMC Public Health 13: 232. doi: 10.1186/1471-2458-13-232.

Hakola, L., M. Hassinen, P. Komulainen, T.A. Lakka, K. Savonen, and R. Rauramaa. 2015. “Correlates of low physical activity levels in aging men and women: The DR's EXTRA study." Journal of Aging and Physical Activity 23: 247-255.

Hunt, K., C. Gray, A. Maclean, S. Smillie, C. Bunn, and S. Wyke. 2014. "Do weight management programmes delivered at professional football clubs attract and engage high risk men? A mixed-methods study.” BMC Public Health 14:50. doi: 10.1186/1471-2458-14-50.

Hunt, K., C. McCann, C.M. Gray, N. Mutrie, and S. Wyke. 2013. "You've got to walk before you run: Positive evaluations of a walking program as part of a gender-sensitized weightmanagement program delivered to men through professional football clubs." Health Psychology 32: 57-65.

Hunt, K., S. Wyke, C.M. Gray, A.S. Anderson, A. Brady, C. Bunn, P.T. Donnan, et al. 2014. "A gender-sensitised weight loss and healthy living programme for overweight and obese men delivered by Scottish Premier League football clubs (FFIT): a pragmatic randomised controlled trial” The Lancet 383 (9924): 1211-1221. doi: 10.1016/S0140-6736(13)62420-4.

Morgan, P.J., D.R. Lubans, R. Callister et al. 2011. “The Healthy Dads, healthy kids randomised controlled trial: efficacy of a healthy lifestyle program for overweight fathers and their children.” International Journal of Obesity 35: 436-437.

Parnell, Daniel, Andy Pringle, Jim McKenna, Stephen Zwolinsky, Zoe Rutherford, Jackie Hargreaves, Lizzie Trotter, Michael Rigby, and David Richardson. 2015. "Reaching Older People with PA Delivered in Football Clubs: The Reach, Adoption and Implementation Characteristics of the Extra Time Programme." BMC Public Health 15: 220. doi:10.1186/s12889-015-1560-5. 
Priest, N., R. Armstrong, J. Doyle, and E. Waters. 2008. "Interventions implemented through sporting organisations for increasing participation in sport." Cochrane Database of Systematic Reviews. Issue 3. Art. No.: CD004812. doi: 10.1002/14651858.CD004812.pub3.

Pringle, A., D. Parnell, S. Zwolinsky, J. Hargreaves, and J. McKenna. 2014. "Effect of a healthimprovement pilot programme for older adults delivered by a professional football club: the Burton Albion case study.” Soccer and Society 15: 902-918.

Robertson, S., and P. Williamson. 2005. "Men and health promotion in the UK: Ten years further on?" Health Education Journal 64: 293-301.

Robertson, S., K. Witty, S. Zwolinsky, and R. Day. 2013. “Men's health promotion interventions: what have we learned from previous programmes?" Community Practitioner 86 (11): 38-41.

Rutherford, Z., B. Gough, S. Seymour-Smith, C.R. Matthews, J. Wilcox, D. Parnell, and A. Pringle. 2014. “'Motivate': the effect of a Football in the Community delivered weight loss programme on over 35-year old men and women's cardiovascular risk factors." Soccer \& Society 15 (6): 951-969.

Sartini, C., S. Goya Wannamethee, S. Iliffe, R.W. Morris, S. Ash, L. Lennon, P.H. Whincup, and B.J. Jefferis. 2015. "Diurnal patterns of objectively measured physical activity and sedentary behaviour in older men.” BMC Public Health 15: 609. doi: 10.1186/s12889-015-1976-y.

Seymour-Smith, S., M. Wetherell, and M. Phoenix. 2002. "My wife ordered me to come!: A discursive analysis of doctors' and nurses' accounts of men's use of general practitioners." Journal of Health Psychology 7: 253-267.

Stewart-Brown, S., A. Tennant, R. Tennant, S. Platt, J. Parkison, and S. Weich. 2009. "Internal Construct Validity of the Warwick-Edinburgh Mental Well-being Scale (WEMWBS): A Rasch analysis using data from the Scottish Health Education Population Survey." Health and quality of life outcomes 19 (7):15. doi: 10.1186/1477-7525-7-15. 
Ward Thompson, C., A. Curl, P. Aspinall, S. Alves, and A. Zuin. 2014. "Do changes to the local street environment alter behaviour and quality of life of older adults? The 'DIY Streets' intervention.” British Journal of Sports Medicine 48: 1059-1065.

World Health Organisation. 2010. Global Recommendations on Physical Activity for Health, Geneva: WHO.

Zwolinsky, S., J. McKenna, A. Pringle, A. Daly-Smith, S. Robertson and A. White. 2013. “Optimizing lifestyles for men regarded as 'hard-to-reach' through top-flight football/soccer clubs." Health Education Research 28: 405-413. 